\title{
¿En qué sentido es libre la potestad constituyente? Una aproximación al concepto de libertad política a partir de la obra de David Hume
}

\section{In Which Sense Is Constituent Power Free? An Approach to the Concept of Political Liberty from David Hume's Work}

\author{
ANTONio Morales MANZO*
}

\begin{abstract}
Resumen
El presente artículo busca explorar una relación entre los conceptos de libertad y potestad constituyente aplicable a contextos de cambio constitucional en el mundo contemporáneo. Utilizando una aproximación filosóficamente escéptica respecto del concepto de libertad, el escrito reflexiona sobre el significado de la libertad política aplicada a nuestra interacción social cotidiana. En línea con algunas de las tradiciones del pensamiento clásico y moderno temprano, el artículo plantea a la vinculación entre potestad constituyente y libertad como una relación complicada. Como se argumentará, no es plausible identificar instancias soberanas de interacción política como momentos de total autonomía para establecer direccionamientos normativos de largo plazo en el seno de una sociedad. Contrario a lo que podría pensarse, sin embargo, la conciencia de la libertad política relativa es un elemento central en el rendimiento políticamente emancipatorio de la potestad constitucional.
\end{abstract}

Palabras clave: Potestad constituyente; libertad de la voluntad; libertad política; republicanismo; nueva Constitución.

\begin{abstract}
This article explores in the relationship between the concepts of liberty and constituent power, applicable to contexts of constitutional change in the contemporary world. Using a philosophically skeptical approach to the concept of liberty, the paper provides a reflection on the meaning of political liberty as applied to our everyday social interaction. In line with some of the traditions of classical and early modern thought, this work outlines the link between constituent power and liberty as a complicated relationship. As will be argued, it is not plausible to identify sovereign instances of political interaction as moments of full autonomy to establish long-term normative guidelines within a society. Contrary to what might be thought, however, the awareness of relative political liberty is a central element in the politically emancipatory performance of constitutional power.
\end{abstract}

Keywords: Constituent power; freedom of the will; political liberty; republicanism; new Constitution.

* LL.M. candidate Northwestern University Pritzker School of Law, Estados Unidos (antonio.morales@law.northwestern.edu). ORCID: http://orcid.org/0000-0003-4736-244X. Artículo recibido el 29 de junio de 2021, y aceptado para su publicación el 30 de julio de 2021. 


\section{INTRODUCCIÓN}

La distinción entre potestad constituyente originaria y derivada parece desempeñar un rol relevante en la comprensión que la comunidad jurídica desarrolla respecto de su práctica interpretativa del derecho. La utilidad de dicha distinción radica en su simpleza: aludiendo a una u otra clase de potestad constituyente, los operadores jurídicos asignan un sentido determinado a las disposiciones jurídicas con consagración constitucional, canalizando con ello desacuerdos políticos o morales específicos a través de los códigos de comunicación del derecho. Esa es precisamente la que podría entenderse como una de las funciones principales de la dogmática jurídica: proveer soluciones simples y estandarizadas a problemas de categorización y aplicación del derecho vigente. ' Sin embargo, lo que puede resultar útil o apropiado para el punto de vista interno del derecho, no necesariamente resulta plausible para la comprensión de las reglas y principios jurídicos desde el punto de vista de otros sistemas de comunicación ${ }^{2}$ o modos de existencia, ${ }^{3}$ tales como la economía o la política. De la misma forma, lo que puede resultar relevante en términos operativos para el funcionamiento del derecho en circunstancias de normalidad, puede transformarse en un problema metodológico cuando el orden jurídico se encuentra en momentos de "crisis de identidad" ${ }_{\mathrm{c}}$ Es relevante la distinción entre potestad constituyente originaria y derivada para evaluar un proceso de creación de una nueva Constitución? ¿Qué clase de relación puede establecerse entre potestad constituyente y potestad constituida para explicar la práctica política de legitimación del dominio de la legalidad en una sociedad (global) como la actual? ¿Cuál es el rol que desempeña el concepto de libertad en la operatividad del poder constituyente, y cómo debe interpretarse la manifestación de su voluntad política? En las siguientes líneas, exploraré un intento de respuesta respecto de las preguntas recién planteadas, limitándome para ello a explorar las consideraciones antedichas a partir de una de las perspectivas disponibles en el pensamiento moderno.

\section{POTESTAD CONSTITUYENTE Y VOLUNTAD LIBRE}

Tradicionalmente, en dogmática constitucional la distinción entre potestad constituyente y potestad constituida se plantearía a partir de los grados de libertad de los cuales dispondría el agente creador de normas jurídicas constitucionales. ${ }^{4}$ Así, mientras el poder constituido se encontraría limitado por las normas de competencia que el poder constituyente define para su posición institucional, el poder constituyente disfrutaría de un ámbito de arbitrio privilegiado: ante la eventual ausencia de normas de competencia que definan sus atribuciones, el poder constituyente sería un poder absoluto, y sería un poder absoluto porque sería plenamente libre. Es tentador a este respecto realizar una analogía entre esta comprensión de los sistemas de

\footnotetext{
${ }^{1}$ ALEXY (2007).

${ }^{2}$ TEUBNER (1988).

${ }^{3}$ LATOUR (2018).

${ }^{4}$ Un exponente relevante de esta perspectiva en la dogmática constitucional contemporánea, influido por Carl Schmitt, es el jurista alemán Ernst Böckenförde. Véase BÖCKENFÖRDE (2000).
} 
normas y una aproximación científica a las leyes de causalidad: el momento del poder constituyente sería en este sentido análogo al momento previo al big bang, aquel instante inicial de gestación del universo que habitamos como seres autoconscientes. En el momento previo al big bang, de acuerdo a las teorías científicas hoy en día predominantes, no habría regularidades o leyes físicas detectables; tampoco habría técnicamente hablando un "momento", en la medida que el tiempo como categoría no existiría (al igual que la categoría del espacio). Solo a partir de esa explosión originaria tendría sentido hablar de leyes físicas y de causalidad, de limitaciones a la interacción entre partículas de materia o fotones de luz. Terminando con la analogía, entonces, el big bang representaría el comienzo de un orden físico constituido por leyes, representando en este paralelo a la potestad constituida; por otro lado, el "instante" previo al big bang correspondería a la potestad constituyente, carente de leyes que circunscribieran su ámbito de acción.

Por más sugerente que pueda parecer la analogía del big bang en términos retóricos, su valor en términos teóricos es reducido. Las leyes físicas se diferencian marcadamente de las leyes en sentido normativo; ${ }^{5}$ para efectos de este análisis, la diferencia principal reside en la carencia de un agente productor de leyes o regularidades físicas en el ámbito de las teorías referentes al big bang. $\mathrm{Al}$ no tener sentido científico la pregunta física por el momento previo al big bang, pierde también sentido científico la pregunta por la interacción entre partículas o fotones de luz previos a ese momento constitutivo. La física, en otras palabras, solo puede responder a interrogantes planteadas respecto del funcionamiento de nuestro universo, con sus limitaciones constitutivas y regularidades sistematizadas por vía de leyes causales. La pregunta que busca responder la distinción entre potestad constituyente y potestad constituida, en cambio, supone un agente productor de normas en ambos momentos, y plantea al arbitrio plenamente libre como el factor diferenciador entre ambas clases de potestad.

La libertad como criterio diferenciador entre potestad constituyente y potestad constituida parece estar más vinculada en términos históricos a una discusión que, en su versión moderna, tiene un origen teológico: la correspondiente al libre albedrío. Atribuir responsabilidad moral a un individuo por los actos que comete, supone asumir que los actos no son meros eventos que le ocurren, sino que la persona en cuestión es el agente que ocasiona dichos actos. ${ }^{6}$ Esta idea de la voluntad libre como la condición de atribución de responsabilidad puede considerarse también como un elemento central de la construcción de la idea de potestad constituyente. Solo en la medida en que el agente sea autor de normas en un contexto de ausencia de constricciones, podrá hablarse de potestad constituyente; existiendo limitaciones (por ejemplo, las correspondientes a normas de habilitación o competencia para modificar normas constitucionales), entonces estaremos ante una potestad constituida y, por lo tanto, restringida en cuanto a su libertad.

Desde la experiencia revolucionaria francesa a fines del siglo XVIII (principalmente, a partir de la influencia intelectual y política del abate Sieyès), el sentido teológico del agente libre productor de las normas que limitan su voluntad se ha extendido desde el plano moral de la responsabilidad individual hacia el plano político de la acción colectiva. Tal como en el

\footnotetext{
KELSEN (1960).

${ }^{6}$ Moya (1990); Davidson (1995).
} 
caso del libre albedrío del individuo, la idea del libre albedrío atribuible a un conjunto de individuos es igualmente polémica. Principalmente, porque esta aproximación al significado de libertad supone unidad de agencia, esto es, que la intención contenida en el acto de creación de normas originarias es única e indiferenciada. Junto a lo anterior, la idea de libre albedrío es polémica por el supuesto mismo de la libertad: ya autores como David Hume a mediados del siglo XVIII planteaban la incoherencia del supuesto de la libertad de la voluntad como requisito para la imputación de responsabilidad. Imputar un acto a una persona supone reconocer la causalidad entre un evento y la intervención en el mundo de un individuo como antecedente directo de ese acto. La idea de libertad planteada por la teología implica una interrupción de esa cadena causal, ¿cómo imputar, entonces, un acto a un agente si el supuesto de libertad interrumpe la secuencia causal que permite reconocer un acto como vinculado a un individuo en particular?

La comprensión teológica de la libertad posee implicancias metafísicas que complejizan innecesariamente la explicación de un fenómeno en sí mismo complejo: la acción política como un caso de agencia colectiva ${ }_{\mathrm{C}}$ Tiene relevancia el concepto de libertad para darle sentido a nuestras prácticas de imputación de responsabilidad (e intencionalidad) en la arena política? La pretensión de este artículo es responder afirmativamente esa pregunta, pero haciendo uso de una tradición de pensamiento político metafísicamente austera, con el objeto de deslindar la noción de libertad política como un constructo simbólicamente relevante para explicar la acción política. A este respecto, resulta pertinente la referencia al pragmatista anglosajón Wilfred Sellars para definir los contornos dentro de los cuales se plantea este ensayo. Sellars acuñó la distinción entre "imagen manifiesta" e "imagen científica" del mundo para delimitar el sentido de nuestras prácticas de interacción social que, en ocasiones, pueden encontrarse en tensión con nuestra comprensión científica del entorno. ${ }^{7}$ Como señala este autor, existe un ámbito de conocimiento crítico y disciplinado que se distingue por un lado de la ciencia, y por otro lado del sentido común; un cuerpo de saberes cuyo objeto central de estudio es la persona, y que constituye el entramado de imágenes a partir de las cuales el ser humano llegó a concebirse como tal en términos históricos. Dicha perspectiva, la imagen manifiesta, evoluciona en paralelo a la imagen científica, interactuando con ella y otorgando las condiciones de descubrimiento a partir de las cuales las correlaciones científicas adquieren operatividad. $\quad$ Lo relevante, por ende, es preguntarse por la posibilidad de sostener la continuidad entre ambas imágenes, de tal forma que la comprensión científica no termine por minar el sentido que le asignamos a nuestras prácticas de interacción en tanto partícipes de ellas. Aplicada al tópico de la potestad constituyente, lo que debiésemos preguntarnos, entonces, es cómo elaborar un concepto de libertad que dé sentido a nuestras prácticas políticas sin que ello se construya en torno a una perspectiva incompatible con nuestra descripción científica del mundo. En el siguiente acápite, expondré la aproximación de David Hume al respecto para avizorar una comprensión posible del concepto de libertad política que pueda satisfacer tales requerimientos.

\footnotetext{
7 SELLARS (1971), pp. 14 y ss.

${ }^{8}$ Sellars (1971), pp. 14 y ss.
} 


\section{DOS CONCEPTOS “HUMEANOS” DE LIBERTAD}

Hume plantea su aproximación al concepto de libertad en el marco de un debate clásico dentro de la modernidad que se extiende hasta la época actual: el correspondiente a la relación entre libertad y determinismo. Asumiendo una teoría unificada de la causalidad, que no distingue entre causación mental y material, el autor escocés desarrolla la idea de necesidad como un aspecto central para comprender su postura respecto del debate recién mencionado. A partir de este criterio diferenciador, Hume propondrá un concepto de libertad por oposición a lo que él denomina la "doctrina de la libertad", elaboración de raíz teológica y predominante en el contexto en que desarrolla su reflexión." Siendo relevante comprender la noción de necesidad y su vínculo con el concepto de causalidad para entender su postura en torno al tópico de la libertad, corresponde primero abordar brevemente este aspecto de la propuesta humeana.

Como aparece de manifiesto en la sección 2.3.1 del Tratado sobre la naturaleza humana, Hume descarta que pueda descubrirse "una conexión última entre los objetos, ni mediante los sentidos ni mediante la razón", no siendo plausible "penetrar tan profundamente en la esencia y composición de los cuerpos como para percibir el principio de que depende su influencia mutua". ${ }^{10}$ Para el autor, "con lo único con lo que estamos familiarizados es con su unión constante, y de esta constante unión surge la necesidad". "La necesidad, por tanto, consta de dos elementos que le son imprescindibles: por un lado, la ya mencionada unión constante, y por otro, la inferencia de la mente. ${ }^{12}$ La noción de causa y efecto es una idea que la mente se forma a partir de la unión constante que posibilita sentir la necesidad. Esta última se trata, por ende, de una percepción, y no de una conclusión del entendimiento. ${ }^{13}$ La teoría unificada de la causalidad que Hume propugna, entiende que las "acciones de la mente" exhiben el mismo tipo de necesidad que aquella perceptible en la relación entre objetos del mundo natural. Las acciones humanas, como consecuencia, dispondrían de los mismos elementos consustanciales a la necesidad en el ámbito de las "acciones de la materia". Al ser la causalidad un mecanismo de asociación entre ideas que tiene su origen en la percepción de la necesidad, no corresponde hacer distinción entre causalidades diversas atendiendo al objeto respecto del cual esta se predica; la causalidad es un fenómeno mental, y como tal no le corresponde discriminar en función del ámbito concreto en el cual adquiere operatividad. Es por esto que Hume sostendrá que el vínculo entre motivos y acciones es equivalente al de las causas y efectos en el mundo material, siendo plausible detectar, tanto en el ámbito de las acciones humanas como en el de las "acciones de la materia", la necesidad que surge de la observación continuada y uniforme

\footnotetext{
${ }^{9}$ Para efectos de este artículo, entenderé el sentido de la expresión "teología" dentro del contexto histórico e intelectual en el cual David Hume plantea su teoría. No obstante, reconociendo la raíz teología cristiana común bajo la cual se plantea la discusión contemporánea al respecto, asumiré también la plausibilidad de aplicar la lectura escéptica de Hume al tratamiento de conceptos jurídicos que derivan lato sensu de esa misma tradición.

${ }^{10}$ Hume (1998), p. 542-543.

"HuME (1998), p. 542-543.

${ }^{12}$ HUME (1998), p. 542-543.

${ }^{13}$ HUME (1998), p. 549.
} 
de las consecuencias y sus causas, descartando con ello una distinción entre necesidad física y moral.

¿Por qué la elaboración de la doctrina humeana de la necesidad respecto de las expresiones necesidad/determinismo trae aparejado el rechazo de lo que Hume identifica como doctrina de la libertad? El escocés entiende por doctrina de la libertad a aquella postura teórica según la cual existe un espacio de autodeterminación del individuo que permite definir a la libertad de la voluntad como la ausencia de constricciones causales, tanto mentales, como físicas. En la medida en que esta doctrina niega que nuestras acciones estén gobernadas por la necesidad, también niega que nuestras acciones puedan ser causalmente explicadas, reduciéndolas a eventos azarosos. ${ }^{14}$ Dado que lo expresado suprimiría la posibilidad de imputar un acto a un agente (pues sin la noción de necesidad no puede realizarse un juicio que aísle aquella existencia particular que es catalogada como causa de la acción), Hume sostiene que la doctrina de la libertad debe ser descartada como vertiente que desempeñe la función de explicar correctamente las acciones humanas.

¿Cuáles son las razones por las cuales la doctrina de la libertad, pese a sus inconvenientes implicancias, es preponderante en el contexto del debate en el que Hume se encuentra inmerso? Tres son los fundamentos que él identifica para entender dicho fenómeno. En primer lugar, la dificultad de persuadirnos a nosotros mismos de que las acciones que realizamos son gobernadas por la necesidad, de tal manera que cuando llevamos a cabo una acción, "nos habría sido absolutamente imposible haber actuado de otra forma". Acá Hume desarrolla una interesante distinción entre dos acepciones del término "libertad", central para este ensayo, con el objeto de identificar aquel elemento de la doctrina de la necesidad que suele provocar repudio y como consecuencia una negación de su valor como teoría. El autor señala que la noción de necesidad parece sugerir que hubiese algo forzoso o violento en el estar determinados causalmente a obrar como efectivamente lo hacemos. Sin embargo, no somos conscientes ni hay pruebas que acrediten esta violencia soterrada que aparentemente obstruye nuestro actuar cotidiano. La percepción anterior es producto de una confusión entre dos aspectos diversos no vinculados entre sí. Es aquí donde la distinción entre libertad de espontaneidad y libertad de indiferencia adquiere relevancia para entender los alcances de la doctrina humeana de la necesidad. Mientras libertad de espontaneidad alude a aquello que se opone a la violencia, libertad de indiferencia refiere a una negación de la necesidad y de la noción de causalidad. Para Hume, es la libertad de espontaneidad la que nos preocupamos por preservar, y su imprecisa vinculación a la libertad de indiferencia ha ocasionado el rechazo erróneamente justificado a la doctrina de la necesidad. Esta doctrina solo niega a la libertad como pretensión teórica (o libertad de indiferencia), la cual plantea la imposibilidad de la causación y de la noción de necesidad como cimientos de la comprensión de la interrelación entre los objetos del mundo (objetos entre los cuales nos incluimos). La libertad de espontaneidad, por ende, corre por un carril separado a la de indiferencia, y constituye una preocupación que la teoría unificada de la causalidad desarrollada por Hume no busca denigrar.

\footnotetext{
${ }^{14}$ PiTsON (2006), p. 218.

${ }^{15}$ HUME (1998), p. 551.
} 
La segunda razón que para Hume explica la preponderancia de la doctrina de la libertad en el debate se vincula con la existencia de "una falsa sensación o experiencia aun de la libertad de indiferencia”, siendo dicha sensación considerada como prueba de la existencia real de esta. ${ }^{16}$ En consonancia con lo expuesto en párrafos anteriores, la necesidad desde el enfoque humeano no es una cualidad del agente, sino del observador, quien infiere comúnmente las acciones a partir de nuestros motivos y carácter. ${ }^{17}$ Poco contribuye por lo tanto a la discusión que pueda concebirse a través de la imaginación una cierta "libertad interior" en el agente, en la medida en que el ser pensante que examina externamente la acción pueda inferir sus causas a partir de la consideración de los resortes motivacionales que inciden en la voluntad del individuo.

Por último, Hume afirma que la influencia de la religión es determinante para comprender la relevancia de la doctrina de la libertad en el foro público. ${ }^{18}$ Según sostiene, la doctrina de la necesidad aparenta ser dañina para la religión y la moral. Sin embargo, esto se debe a una confusión de los partidarios de la doctrina de la libertad. La necesidad es un requisito imprescindible para la plausibilidad de las instituciones cuya función consiste en regular la conducta de los agentes que se desenvuelven en comunidad. Las leyes humanas, de acuerdo al escocés, se cimientan en el otorgamiento de premios y castigos, y su efectividad se presupone al asumir que estos afectan en su calidad de motivos a la mente de los agentes, produciendo en virtud de lo anterior las acciones consideradas buenas, e impidiendo a su vez las calificadas como malas. ${ }^{19}$ Si no fuese posible entender la injerencia de dichos incentivos sobre los agentes como causas (motivos) de la acción, el resultado para la efectividad de las leyes humanas sería lamentable. En efecto, la vigencia de estas quedaría en entredicho, al no hacerse operativas a partir del carácter no causal de sus directrices en las acciones humanas. Desde la perspectiva de Hume, lo mismo ocurriría con las leyes divinas, siendo por ende contradictoria la suspicacia que la doctrina de la necesidad genera entre los individuos ligados a la religión. Junto a lo indicado, la imputación de responsabilidad a los agentes intencionales por las acciones que realizan sería inviable, en tanto sin la causación no se dispondría de un criterio que permitiese discriminar entre este tipo de comportamientos y aquellos accidentales o casuales, que ocurren sin la intervención de la voluntad del agente. En definitiva, la necesidad es una condición sine qua non para los fines que la misma doctrina de la libertad dice promover.

Queda a la vista que la voluntad tiene un rol central en la perspectiva de Hume acerca de la causalidad, al constituirse en el ámbito en donde la necesidad opera al nivel de lo que él

\footnotetext{
${ }^{16}$ HuMe (1998), p. 551.

${ }^{17}$ HUME (1998), p. 553.

${ }^{18}$ HUME (1998), p. 553.

${ }^{19}$ HuMe (1998), p. 555. Véase también PiTsOn (2006), pp. 218-219.
} 
califica como "acciones mentales". ${ }^{20}$ Hume no busca situar a la libertad como un tópico respecto del cual tenga sentido pronunciarse en lo concerniente a la voluntad; su proyecto, en cambio, consiste en identificar los factores que inciden en la determinación de la voluntad de los agentes intencionales a partir de los elementos que la necesidad permite detectar en la regularidad del comportamiento humano, infiriendo por medio de lo anterior las constantes apreciables. El autor sugiere que su postura no conlleva una modificación de la perspectiva dominante en su contexto intelectual respecto de la voluntad (al contrario de lo que, desde la vereda de la doctrina de la libertad, sería la explicación para entender el giro argumentativo de la propuesta humeana), sino una extensión de la metodología empleada para su estudio al ámbito de los objetos materiales. ${ }^{21}$ Esto es coherente con la teoría unificada de la causalidad de Hume, y busca resaltar el carácter independiente de los objetos de la naturaleza que la necesidad desempeña a nivel cognitivo. En resumen, la visión del autor respecto de la causalidad surge como una respuesta a una descripción errónea del funcionamiento de la voluntad (la contenida en la doctrina de la libertad), y se extiende desde ahí a la elaboración de una teoría general de la causalidad, que tiene aplicación tanto en el ámbito de las acciones humanas, como en el ámbito de la interacción entre objetos del mundo natural.

¿Cuál es, entonces, la postura de Hume en relación a la libertad? El autor parece rechazar la plausibilidad de la libertad de la voluntad en sí misma, en la medida en que esto acarrearía la indeterminación causal de las acciones de los agentes intencionales, y tendría como consecuencia además la negación de la posibilidad de responsabilizar a los sujetos por la realización de comportamientos valorados como buenos o malos en el seno de una comunidad. Hume, en este sentido, cabría dentro de lo que Ayer considera como el conjunto de autores que han definido a la libertad como la "consciencia de la necesidad". Sin embargo, como señala este último autor, ¿no es la definición antedicha de libertad una que desvirtúa por completo el sentido del término en la discusión respecto del tema? En efecto, uno puede ser consciente de las causas que lo impulsan a actuar como efectivamente actúa, sin que ello implique ser libre en el sentido usual de la palabra (esto es, de hecho, compatible con una tesis determinista). Hume no es insensible a esta crítica, y es por eso que introduce la distinción entre libertad de espontaneidad y libertad de indiferencia ya expuesta, de la cual Ayer hace eco al sostener con pertinencia que la oposición relevante no es la que se presenta entre libertad y necesidad, sino entre libertad y coerción. ${ }^{23}$ Efectivamente, es al nivel de las relaciones interpersonales en donde puede encontrarse el factor que limita la libertad del agente; la violencia así entendida difiere de la pretendida fuerza que la doctrina de la libertad de indiferencia dice percibir en las relaciones causales entre eventos en el mundo.

\section{LIBERTAD Y COERCIÓN: HACIA UNA APROXIMACIÓN REPUBLICANA AL CONCEPTO DE LIBERTAD POLÍTICA.}

\footnotetext{
${ }^{20}$ HuMe (1998), p. 554.

${ }^{21}$ Hume (1998), p. 555

${ }^{22}$ AYER (1982), p. 18.

${ }^{23}$ AYER (1982), p. 19.
} 
La perspectiva de David Hume desarrollada en el acápite anterior posee un rendimiento interesante al extrapolarla al contexto de la acción política. ${ }^{24} \mathrm{Su}$ posición respecto de la libertad de la voluntad permite elaborar una aproximación que delimita el problema metafísico de la libertad respecto del plano simbólico de la acción considerada como "libre". Este es el aporte principal que para estos efectos se puede desprender de la distinción entre libertad de espontaneidad y libertad de indiferencia, la cual marca una ruptura con aproximaciones de índole metafísico al tópico de la libertad humana ¿De qué hablamos, entonces, cuando hablamos de libertad en el plano político? Ciertamente no de agentes libres en el sentido de estar ausentes de toda clase de constricciones; la libertad política es la actitud reflexivamente consciente de personas que, identificando situaciones de coerción simbólica que restringen su ámbito de acción, buscan realizar intencionalmente aquellos comportamientos que se desprenden de lo que Hume denomina como sus pasiones o, en un sentido más neutro, de su conjunto motivacional. ${ }^{25}$ Es en el ámbito de las relaciones interpersonales donde surgen las constricciones relevantes para un concepto de libertad política, y dichas constricciones son constitutivas de la experiencia social e institucional de la libertad. En otras palabras, la libertad política es el horizonte de acción emancipatoria de relaciones interpersonales planteadas en dinámicas de dominación, asumiendo que dichas dinámicas de dominación son, de hecho, constitutivas de aquellas relaciones interpersonales.

El concepto humeano de libertad de espontaneidad posee ciertamente elementos asimilables a la tradición republicana de la modernidad temprana, recuperada parcialmente en la literatura anglosajona de la segunda mitad del siglo XX a través de la construcción del concepto de libertad entendida como ausencia de dominación (arbitraria). ${ }^{26}$ Tal como en la noción republicana de libertad política, el concepto de libertad de espontaneidad permite plantearse la pregunta por la institucionalización de la práctica de la acción política en una sociedad a través de la traducción jurídica de la libertad política en el concepto y práctica de la libertad civil. La distinción entre potestad constituyente y constituida adquiere sentido, de este modo, cuando la pregunta por la libertad política se responde a través de la creación de instituciones que tienen la expectativa de canalizar instancias de no dominación arbitraria entre personas que, coordinadamente, participan como iguales en la interacción social.

En esta etapa del argumento, corresponde introducir distinciones ulteriores con el objeto de precisar el rol de la libertad en la acción política institucional, en contraste a la acción política no institucionalizada. Leyendo en este sentido a Niccolò Machiavelli, es preciso diferenciar entre el momento de la acción política como una reacción meramente negativa a la dominación y el momento de la acción política como el proceso de instauración de un régimen de gobierno. La distinción Machiaveliana entre acontecimiento y forma (y, más directamente, entre fortuna y virtù), adquiere aplicación práctica cuando somos capaces de diferenciar entre la acción política como rechazo a la dominación y la acción política como orientada a la

\footnotetext{
${ }^{24}$ Este artículo asume que el ejercicio de aplicar la perspectiva de Hume acerca de la libertad de la voluntad al ámbito de la acción política es una exploración inspirada en una visión humeana, y no una lectura textual de un concepto de lo político desarrollado por Hume.

${ }^{25}$ SMITH (1994).

${ }^{26}$ Véase a este respecto PETTIT (1997), SKInNER (1984).
} 
constitución de una forma para gobernar. ${ }^{27}$ Corresponde destacar que en esta interpretación de Machiavelli el momento de libertad política pre-institucional es una negación radical de la dominación, consistiendo por lo tanto en un momento que en sí mismo no es propositivo, sino radicalmente negativo. En otras palabras, la acción política en su etapa pre-institucional no busca imponer una voluntad, sino emanciparse de relaciones de dominación eventualmente arbitraria; el sentido de la acción política en este nivel es, en este sentido, completamente negativo, no positivo. ${ }^{28}$ Como señala Miguel Vatter, recurriendo para ello a Hanna Arendt, la libertad política instanciada en esta potestad constituyente pre-institucional contiene no meramente una pretensión de ausencia de dominación, sino la emancipación de cualquier forma de gobierno. ${ }^{29}$ Acá la metáfora del big-bang adquiere connotación política, pero asumiendo un significado distinto al expuesto al comenzar este ensayo: dicha metáfora puede contribuir a explicar el significado de la potestad constituyente en este momento preinstitucional precisamente porque el impulso emancipatorio de la acción política en este nivel no tiene una voluntad definida. La potestad constituyente, que proporciona indirectamente el impulso para adoptar una potencial nueva forma de gobierno (y, con ello, una nueva forma de dominación), carece de voluntad más allá de la negación de un orden constitutivo de relaciones cimentadas sobre la práctica de la dominación.

El primer sentido de poder constituyente como una magnitud política pre-institucional, desarrollado en el párrafo anterior, debe entenderse en el marco de lo que la óptica republicana reconoce como la iteración constante entre emancipación y orden. La lectura de Machiavelli aquí desarrollada identifica, entonces, no solamente un momento pre-institucional como negación de un orden ilegítimo, sino también un momento institucional para el ajuste o instauración de un orden que procese dicha voluntad negativa. ${ }^{30}$ En este segundo momento, la libertad política deja de manifestarse de manera negativa y se erige como el impulso para la adopción de un régimen de gobierno. La perspectiva republicana como se presenta en estas líneas, por lo tanto, supone un rol dual y diferenciado del poder constituyente como las dos caras de interacción con el poder institucionalizado: por un lado, como negación de un orden de dominación; por otro, como la pretensión de instauración de un orden legítimo (o, en términos contemporáneos, como una forma de dominación no arbitraria anclada a la idea de dominio legal). ${ }^{31}$ Desde el punto de vista interno a un orden jurídico, la noción relevante de poder constituyente es esta segunda acepción del término: el concepto de poder constituyente instituido para brindar un cierre auto-referencial a la institucionalidad de un orden de gobierno anclado en la autoridad de la ley, compatible en clave contemporánea con la idea de un estado constitucional de derecho. ${ }^{32}$

\footnotetext{
${ }^{27}$ GNOLi \& SASSO (2013), Machiavelli (2016), VATTER (2000).

${ }^{28}$ Planteo la distinción a partir de la categorización del concepto de libertad desarrollado por Berlin. Véase BERLIN (1982).

${ }^{29}$ VATTER (2012), pp. 71 y ss.; pp. 258 y ss.

${ }^{30}$ Machiavelli (2012; 2016); SASSO (2016).

${ }^{31}$ VATTER (2012), pp. 245 y ss.

${ }^{32}$ TEUBNER (1988); KJAER (2011, 2020).
} 
En síntesis, existe una tensión entre el concepto de potestad constituyente y el de potestad constituida para efectos de entender las dinámicas de acción política y consolidación institucional de un orden jurídico como proceso en perspectiva histórica. El poder constituyente como un poder pre-institucional es radicalmente negativo, en tanto no posee una voluntad definida más allá del levantamiento contra una forma de gobierno o, con mayor precisión, contra cualquier forma de gobierno. En este nivel de la libertad política en sentido republicano, la libertad como ausencia de dominación bien podría entenderse como libertad en tanto ausencia de gobierno. No obstante, dado que este momento coyuntural de reacción a un orden es una contingencia temporalmente limitada, el paso siguiente consiste en la instauración de un orden actualizado: la potestad constituyente no instituida da lugar, de esta forma, a la potestad constituyente instituida por el ordenamiento jurídico, la cual busca cimentarse como autoridad legítima y abrir el camino a una sociedad donde la libertad política se consagra institucionalmente como libertad civil. Este proceso muestra la iteración entre emancipación y orden que conforma la descripción de la acción política en clave republicana: no hay orden estable sin la posibilidad de canalizar la insatisfacción respecto de los términos de dominación bajo los cuales, necesariamente, cualquier forma de gobierno opera. El momento plebeyo de la potestad constituyente no instituida es, entonces, condición para la estabilización del momento patricio de un orden jurídico. ${ }^{33}$ En otras palabras, un orden institucional no puede pretender estabilidad si no abraza momentos de inestabilidad como parte constitutiva de su historia institucional.

A partir de lo expuesto anteriormente, puede colegirse que el concepto de potestad constituyente que utiliza el punto de vista interno a la práctica institucional del derecho es una noción diferenciada respecto de la potestad constituyente que explica el proceso de ajuste de un orden jurídico. En efecto, cuando la dogmática constitucional distingue entre potestad constituyente originaria y derivada, lo hace en referencia a la voluntad política que se plantea la consagración de una forma de gobierno a través del derecho. Esta pretensión de soberanía, en la tradición republicana de la modernidad temprana, es ajena a la noción de potestad constituyente como acontecimiento político pre-institucional que canaliza el deseo de libertad (de espontaneidad) entendida como ausencia de dominación. La pregunta por el concepto de potestad constituyente que señala habitualmente la dogmática constitucional desde el punto de vista interno del derecho es, por lo tanto, una pregunta acerca de la voluntad del "soberano" que desea instaurar o actualizar un orden. La distinción entre potestad constituyente originaria y derivada tiene lugar dentro de los límites del derecho, y busca deslindar la frontera entre el deseo de gobernar y el deseo de, simplemente, no ser gobernado.

${ }^{33}$ VATTER (2012), pp. 37 y ss 


\section{POTESTAD CONSTITUYENTE INSTITUIDA Y LIBERTAD POLÍTICA}

En el acápite anterior se abordó en qué sentido el momento pre-institucional de la potestad constituyente es libre; también, se presentó el carácter negativo de la voluntad canalizada a través de dicha instanciación del concepto de libertad política. Lo que corresponde señalar ahora es en qué sentido la potestad constituyente instituida por el derecho es libre, y cómo se define su voluntad.

La pregunta por la libertad política de la potestad constituyente instituida por el derecho debe responderse asumiendo la imposibilidad de la libertad absoluta como punto de partida del argumento. Teniendo a la vista el vínculo entre potestad constituyente y soberanía para la instauración (o continuación) de una forma de gobierno, la libertad de la voluntad política canalizada a través esta instancia institucional es, por definición, limitada. Usando terminología republicana clásica, el momento patricio de la potestad constituyente instituida será tal, aún cuando sean sectores plebeyos quienes ostenten parcial o totalmente poder en dicho estadio de un proceso histórico. La instauración o actualización de un orden para gobernar es, en términos actitudinales, contrario al impulso emancipatorio que explica el comienzo de un proceso constituyente en primer lugar. ${ }^{34}$ En la fase instituida de un proceso constituyente se produce, además, el retorno a lo que podría denominarse como 'circunstancias de normalidad' en las dinámicas de interacción social mediadas por el derecho. Bajo este escenario, las relaciones interpersonales constituidas contingentemente como relaciones de dominación son elementales para entender las dinámicas de acción política. Pretender que una potestad constituyente instituida es plenamente libre implica asumir que quienes toman decisiones operan en un contexto de ausencia absoluta de relaciones constituidas como lazos de dominación. Aludiendo nuevamente a David Hume, la libertad de la voluntad como consciencia de la necesidad debería llevar también a entender a la libertad política como consciencia de la existencia de constricciones que restringen, arbitrariamente o no, la espontaneidad de las relaciones sociales. Es aquí donde reside el potencial emancipatorio de una potestad constituyente instituida: en reconocer sus limitaciones para el proceso de consagración de espacios efectivos de libertad política amparados por el derecho, en lugar de asumir el discurso de la plena autonomía como narrativa vacía de contenido ante las circunstancias factuales en que opera la libertad de espontaneidad en clave política.

Ahora bien, ¿cómo identificar la voluntad manifestada a través del ejercicio de la potestad constituyente instituida? Dada la coyuntura histórica en la cual se escriben estas líneas, enfocaré la respuesta en el caso de un órgano colegiado como instancia de ejercicio de esta clase de potestad. Tomando en consideración que la potestad constituyente en este estadio institucional conlleva la posibilidad de legitimación del ejercicio del dominio a través del derecho, es preciso observar el carácter conflictivo e internamente diferenciado de la voluntad de cualquier conjunto de individuos orientados a la imposición de reglas jurídicas con esa expectativa de legitimación del poder. La potestad constituyente instituida, bajo esta lectura, no es una instancia decisoria construida sobre la unidad de agencia de quienes la ejercen. Debido a que el conflicto político es el que define la iteración histórica entre inestabilidad y orden, pierde sentido referirse a la acción política con una perspectiva teleológica orientada a la resolución

\footnotetext{
${ }^{34}$ VATTER (2012), pp. 272 y ss.; véase también GNOLI y SASSO, pp. 79 y ss. (capítulo IV).
} 
del conflicto. La armonización de intereses contrapuestos es, de esta manera, temporalmente limitada. Un buen diseño de una forma de gobierno se caracteriza por lograr un arreglo institucional orientado a la estabilización del orden, sin embargo, dicha estabilización conllevará la ocurrencia de un acontecimiento político posterior que traerá ineludiblemente la posibilidad de inestabilidad y, con ello, de un 'regreso al origen' en términos de las demandas de legitimación del dominio. ${ }^{35}$

El carácter dinámico de los intereses canalizados a través de la acción política tiene como consecuencia la articulación variable de aquellos en el proceso constitucional, tanto en el ejercicio de la potestad constituyente (instituida) originaria, como en el ejercicio de la potestad constituyente (instituida) derivada ${ }_{\mathrm{C}}$ Es correcto, entonces, atribuirle una voluntad propositiva a un órgano colegiado que ejerza alguna de las potestades recién mencionadas? Sí, en la medida en que se emplee una aproximación metafísicamente austera para adscribirle intencionalidad.

Un órgano colegiado integrado según la aplicación de un principio democrático de representación, y que toma decisiones según un principio democrático de mayoría (o de supra mayoría), no posee una única voluntad constante en términos diacrónicos. La ausencia de una voluntad única e indubitable no se debe solamente a la multivocidad de intereses representados, sino también a la inexistencia de una única respuesta correcta a las interrogantes planteadas en la vida en común. ${ }^{36}$ La articulación variable de una diversidad de intereses conlleva, a su vez, otra consecuencia relevante: la distinción entre aliados y contrincantes es fluida y dinámica, debido al carácter contingente de las alianzas en un marco institucional donde lo que está en juego es la constante disputa por el reconocimiento de espacios de libertad política entendida como ausencia de dominación.

\section{CONSIDERACIONES FINALES}

Las nociones de potestad constituyente y de libertad planteadas desde el punto de vista de la acción política no institucionalizada poseen una connotación distinta al uso de ambos conceptos desde la perspectiva de la acción política institucional. En el momento no institucional de la acción política, el concepto de potestad constituyente permite referirse a la voluntad negativa de un conjunto de individuos que reaccionan a situaciones sistémicamente obstructivas de lo que, a través de una lectura política de la obra de David Hume, ha sido calificado como libertad de espontaneidad. Esta comprensión de la libertad política encuentra un 'parecido de familia' reconocible con la tradición republicana de la modernidad temprana, a través de su comprensión de libertad como ausencia de dominación. La peculiaridad de este momento no institucional de la acción política es que permite observar contingencias sociales donde lo que impera es una acepción radicalmente negativa de libertad en sentido republicano, convirtiendo el deseo de ausencia de dominación en el deseo de, simplemente, no ser gobernado. La búsqueda de instancias de socialización donde no existan vínculos constituidos en torno a la idea de dominación es una intuición fundamental del republicanismo moderno,

\footnotetext{
${ }^{25}$ VATTER (2012), pp. 157 y ss.

${ }^{36}$ MORAles (2010).
} 
y la obra de Machiavelli es una manifestación de lo anterior. Sin embargo, la tensión dentro de la misma tradición republicana se identifica una vez que se constata que los acontecimientos políticos que postulan la ausencia absoluta de dominación son coyunturas temporalmente limitadas: el dominio es un elemento implicado en cualquier forma de organización social, también en aquellas que surgen con el objeto de terminar con dinámicas de dominación. Es por esto que el rescate del republicanismo en clave contemporánea se centra en la búsqueda de un diseño institucional que permita distinguir instancias de dominación arbitraria respecto del dominio legal como esquema no arbitrario de dominación. Lo que comparten ambas lecturas del republicanismo (y, me atrevería a decir, la comprensión de libertad desarrollada por David Hume), es que la libertad de los agentes que participan en la interacción política es necesariamente limitada. Esto se hace patente cuando se analiza la acción política institucional, una vez que el acontecimiento político tendiente a la instanciación del concepto de potestad constituyente en su momento radicalmente negativo ya ha tenido lugar. En el ámbito institucional, la acción política es constituida y mediada por el derecho. Desde el punto de vista jurídico, entonces, la noción de potestad constituyente adquiere un significado diferenciado, en tanto el momento jurídicamente institucionalizado de la potestad constituyente tiene por finalidad instaurar o actualizar una forma de gobierno con miras a brindar legitimación al ejercicio de la soberanía. En este momento institucional, por lo tanto, la voluntad política sí tiene un contenido propositivo, consistente en otorgar legitimación a un orden que siempre presenta la posibilidad de tornarse (o volver a ser) ilegítimo.

La noción de libre albedrío provee una aproximación descriptivamente inadecuada para explicar la interacción política. El concepto de libre albedrío aplicado al ámbito político es análogo a lo que David Hume cataloga como libertad de indiferencia, debido a que no identifica las constricciones presentes en las relaciones sociales como un elemento central para definir el sentido político de la libertad. El potencial emancipatorio de la acción política reside en la conciencia de la existencia de aquellas instancias arbitrarias o no arbitrarias de dominación que atraviesan, de facto o de iure, las dinámicas de interacción social. Es en la constatación de la libertad como una construcción históricamente situada e inacabada donde descansa la promesa de legitimación de un orden; de la misma manera, es en la constatación del horizonte limitado del cumplimiento de esa promesa de libertad política donde se encuentra el anticipo de la contingencia que pondrá en jaque a ese mismo orden. Bajo la óptica republicana, las coyunturas constituyentes incuban las promesas y expectativas que serán inevitablemente defraudadas y canalizadas por medio de una desestabilización de una forma de gobierno. Diferenciar entre una potestad constituyente instituida y una potestad constituyente no instituida permite retener la importancia del conflicto como la constante en la acción política orientada a la consagración institucional de la libertad entre individuos que aspiran a ser reconocidos como políticamente iguales. Olvidar la posibilidad de la inestabilidad en la impredecible evolución política de las sociedades no elimina escenarios de crisis; simplemente, contribuye a profundizarlos. De la misma manera, omitir las dinámicas de dominación que atraviesan las relaciones sociales no aporta más libertad, sino que debilita el potencial emancipatorio de una voluntad política constituyente orientada a la estabilización de una forma de gobierno que consagre institucionalmente espacios de libertad política en la interacción social. 


\section{BIBLIOGRAFÍA CITADA}

AleXy, Robert (2007). Teoría de la Argumentación Jurídica (trad. Manuel Atienza e Isabel Espejo). Madrid: Centro de Estudios Constitucionales y Políticos.

AYER, A.J. (1982). "Freedom and necessity”, en Free Will (ed. Gary Watson), Oxford: Oxford University Press.

Berlin, Isaiah (1982). "Four essays on liberty". Oxford: Oxford University Press.

BÖCKENFÖRDE, Ernst (2000). Estudios sobre el estado de derecho y la democracia (trad. Rafael de Agapito Serrano). Madrid: Trotta.

Davinson, Donald (1995). Acciones, razones y causas (trad. del Instituto de investigaciones filosóficas de la UNAM). En Ensayos sobre acciones y sucesos, Barcelona: Crítica, pp. 17-36.

GnOLI, Antonio \& SASSO, Gennaro (2013). I corrotti e gli inetti. Conversazioni su Machiavelli. Milano: Bompiani.

Hume, David (1998). Tratado de la naturaleza humana (trad. F. Duque), Madrid: Tecnos.

KJAER, Poul (2011). "Law and Order within and Beyond National Configurations", en: Poul Kjaer, Gunther Teubner \& Alberto Febbrajo (eds.), The Financial Crisis in Constitutional Perspective. The Dark Side of Functional Differentiation. Oxford: Hart Publishing, pp. 395-430.

(2020). "The Law of Political Economy: an Introduction”, en: Poul Kjaer (ed.), The Law of Political Economy: Transformation in the Function of Law. Cambridge: Cambridge University Press, pp. 1-30.

Kelsen, Hans (1960). Teoría Pura del Derecho. Buenos Aires: Eudeba.

Latour, Bruno (2018). An Inquiry into modes of existence. An anthropology of the moderns (trad. Catherine Porter). Cambridge, MA: Harvard University Press.

Machiavelli, Niccolò (2012). II principe. Milano: Bur. (2016). Discorsi sopra la prima deca di Tito Livio. Milano: Bur.

Morales, Antonio (2010). "Metafísica, objetividad y derecho: reflexiones en torno a la tesis de la respuesta correcta”, en M. E. Orellana Benado (ed.), Causas perdidas. Ensayos de Filosofía Jurídica, Política y Moral. Santiago: Catalonia, pp. 81-99.

Moya, Carlos (1990). "Philosophy of action". Cambridge: Polity Press.

PetiT, Phillip (1997). "Republicanism. A Theory of Freedom and Government”. New York: Oxford University Press.

Pitson, Tony (2006). "Liberty, necessity and the will”, en The Blackwell guide to Hume's Treatise (ed. SaulTraiger). Oxford: Blackwell, pp. 216-232.

Sasso, Gennaro (2016). Introduzione. En Machiavelli, Niccolò, Discorsi sopra la prima deca di Tito Livio. Milano: Bur. 
Sellars, Wilfrid (1971). Ciencia, percepción y realidad (trad. V. Sánchez de Zavala), Madrid: Tecnos.

SkINNER, Quentin (1984). "The Idea of Negative Liberty: Philosophical and Historical Perspectives." En Philosophy in History (eds. R. Rorty, 1B. Schneewind, and Q. Skinner). Cambridge: Cambridge University Press.

SMITH, Michael (1994). The moral problem. Oxford: Blackwell.

Teubner, Gunther (1988). Evolution of Autopoietic Law. En Autopoietic Law - A New Approach to Law and Society. New York: De Gruyter, pp. 217-241.

VATTER, Miguel (2000). Between form and event. Machiavelli's theory of political freedom. Boston: Kluwer Academic Publishers. (2012). Constitución y resistencia: ensayos de teoría democrática radical. Santiago: Ediciones Universidad Diego Portales. 